\title{
Decreased Amygdala CRF-Binding Protein mRNA in Post-Mortem Tissue from Male but not Female Bipolar and Schizophrenic Subjects
}

\author{
Ryan J Herringa ${ }^{1,5}$, Patrick H Roseboom ${ }^{*, 1,2,3,5}$ and Ned H Kalin ${ }^{1,2,4}$ \\ 'Neuroscience Training Program, University of Wisconsin-Madison, Madison, WI, USA; ${ }^{2}$ Department of Psychiatry, University of \\ Wisconsin-Madison, Madison, WI, USA; ${ }^{3}$ Department of Pharmacology, University of Wisconsin-Madison, Madison, WI, USA; \\ ${ }^{4}$ Department of Psychology, University of Wisconsin-Madison, Madison, WI, USA
}

\begin{abstract}
Stressful life events are commonly associated with the onset and maintenance of psychopathology and much research has focused on the role of the corticotropin-releasing factor (CRF) system in mediating psychopathology. Since CRF serves to integrate the stress response, it is possible that the CRF system plays a role as a neurochemical linkage between stress and psychopathology. CRF-binding protein (CRF-BP) is thought to modulate CRF activity by decreasing its actions. Therefore, in some psychopathological states, alterations in CRF-BP function may contribute to dysregulation of the CRF system. Since the amygdala CRF system mediates stress- and anxietyrelated behaviors and alterations in amygdala function are associated with psychopathology, we examined amygdala CRF-BP gene expression in post-mortem brains from subjects with major depression, bipolar disorder, and schizophrenia as well as in controls. In addition to characterizing the anatomic distribution of CRF-BP mRNA in the human amygdala and medial temporal lobe region, we found a significant decrease in CRF-BP mRNA levels in the basolateral amygdala of male bipolar and male schizophrenic subjects and the lateral amygdala of male bipolar subjects. These results raise the possibility that men with decreased amygdala CRF-BP may be more vulnerable to the effects of stress exposure on the etiology or maintenance of bipolar disorder or schizophrenia. Neuropsychopharmacology (2006) 3 I, | 822-1831. doi: I0.1038/sj.npp. I30 I038; published online 8 February 2006
\end{abstract}

Keywords: $\mathrm{CRH}$; gender; neuropeptides; depression; mental illness; psychopathology

\section{INTRODUCTION}

Stressful life events frequently precede the onset of psychopathology such as depression and anxiety disorders (Brown et al, 1987; Dunner et al, 1979; Hammen et al, 1992), and stress has been linked to the exacerbation of schizophrenic symptoms (Norman and Malla, 1993, 1994). Corticotropin-releasing factor (CRF) is a key mediator of the behavioral, autonomic, and endocrine responses to stress (Dunn and Berridge, 1990). As such, the CRF system is a prime candidate to mediate the effects of stress exposure on the development and/or maintenance of psychopathology. The CRF system consists of four ligands (CRF, urocortin 1, 2, and 3), two receptors $\left(\mathrm{CRF}_{1}\right.$ and $\left.\mathrm{CRF}_{2}\right)$ and a binding protein (CRF-BP). Evidence points to

\footnotetext{
*Correspondence: Dr PH Roseboom, Department of Psychiatry, University of Wisconsin-Madison, 600I Research Park Blvd, Madison, WI 537|9-| |76, USA, Tel: + I 608263 0504, Fax: + I 6082659362 , E-mail: roseboom@wisc.edu

${ }^{5}$ These authors contributed equally to this work.

Received 27 July 2005; revised 28 October 2005; accepted II December 2005

Online publication: 4 January 2006 at http://www.acnp.org/citations/ Npp0 I0406050477/default.pdf
}

dysregulation of the CRF system in a number of psychiatric disorders. For example, cerebrospinal fluid (CSF) levels of CRF are elevated in some subjects with depression, obsessive-compulsive disorder, posttraumatic stress disorder, and alcohol withdrawal (Arborelius et al, 1999; Mitchell, 1998). In depressed individuals, CSF CRF levels also tend to normalize with successful antidepressant treatment, suggesting that high CSF CRF is state-dependent and not a trait marker for depression (Mitchell, 1998). Of note, in non-human primates, an anxious endophenotype is also associated with elevated CSF CRF levels (Kalin et al, 2000). Furthermore, preclinical studies in rodents and primates demonstrate that increased CRF activity is associated with increases in anxiety- and depression-related behavioral responses (Dunn and Berridge, 1990; Kalin, 1985; Kalin et al, 1983; Koob and Heinrichs, 1999).

In view of the fundamental role of CRF in the stress response, it is possible that alterations in this system may mediate the effects of stress on the expression and maintenance of psychopathology. Along these lines, both CRF mRNA and the number of CRF containing cells are increased in the hypothalamic paraventricular nucleus of depressed suicide victims (Raadsheer et al, 1995). Also, a reduction in CRF binding sites has been reported in the 
frontal cortex from depressed suicide victims (Nemeroff et al, 1988), as well as increased CRF content and decreased $\mathrm{CRF}_{1} \mathrm{mRNA}$ in the frontopolar cortex (Merali et al, 2004). These findings are consistent with increased levels of CRF ligand availability in depressed subjects. However, two other studies found no differences in CRF content (Leake et al, 1990) or CRF receptor binding (Hucks et al, 1997; Leake et al, 1990) in the frontal cortex of post-mortem samples obtained from depressed subjects, suggesting that the cortical alterations in the CRF system may be a variable finding. Finally, in a small open label study, administration of a small molecule $\mathrm{CRF}_{1}$ antagonist appeared to reduce the symptoms of depression (Zobel et al, 2000).

In contrast to CRF and its receptors, fewer studies have examined the role of CRF-BP in relation to psychopathology. CRF-BP binds CRF with an affinity comparable to that of the CRF receptors and is thought to buffer the actions of CRF (Behan et al, 1995). Dysregulation of CRF-BP may therefore play an important role in the genesis of the hyperactive CRF state that appears to be associated with depression and perhaps other psychopathologies. Indeed, a recent study suggests that alterations in CRF-BP may contribute to the genetic vulnerability to depression. In a Swedish population, variants of the CRF-BP gene were associated with the development of major depression (Claes et al, 2003). Interestingly, the polymorphisms for CRF-BP that correlated with depression were found in noncoding regions of the gene (intron 6 and the $3^{\prime}$ untranslated region). This finding raises the possibility that expression levels, and not function, of the CRF-BP may be altered in depressed individuals. The only published study to examine levels of CRF-BP gene expression in psychopathology reported no alterations in CRF-BP $\mathrm{mRNA}$ in the frontal cortex of suicide victims $v s$ controls (Merali et al, 2004).

Owing to the role of CRF-BP as a modulator of CRF activity, we examined CRF-BP gene expression in the amygdala and surrounding areas in post-mortem tissue from subjects with major depression, bipolar disorder, schizophrenia, and age-, sex-, and post-mortem delay matched controls. The amygdala region was selected since it is an important anatomical substrate for the actions of CRF (Koob and Heinrichs, 1999), and alterations in amygdala function are associated with some types of psychopathology (Davidson, 2002; Drevets and Raichle, 1995; Schwartz et al, 2003). Given the proposed buffering role for CRF-BP and the data indicating that stress exacerbates the symptoms of psychiatric illness, we hypothesized that CRF-BP levels would be reduced in subjects with psychiatric disorders compared to controls. It is also of interest that estrogen plays a role in regulating CRF-BP (Speert et al, 2002; van de Stolpe et al, 2004) and this could be related to the well established differences in the expression of psychopathology between males and females. Therefore, we examined the extent to which diagnostic-related changes in CRF-BP expression were gender specific. Reductions in CRF-BP, particularly in the amygdala, could contribute to a hyperactive CRF state and increased sensitivity to the CRF-dependent effects of stress. In addition to assessing potential changes in CRF-BP mRNA expression in relation to these illnesses, this study characterized the distribution of CRF-BP mRNA in the human amygdala and medial temporal lobe region.

\section{METHODS AND MATERIALS}

\section{Subjects}

Fresh-frozen human amygdala coronal sections $(14 \mu \mathrm{m}$ width) were obtained from the Stanley Foundation Neuropathology Consortium (Torrey et al, 2000). This brain bank consists of 15 normal controls and 15 subjects each with major depression, bipolar disorder, and schizophrenia for a total of 60 samples. Subjects are matched for age, sex, and post-mortem delay (Table 1). The tissue used in this study contained excellent- to good-quality mRNA as determined by the Stanley Foundation (Torrey et al, 2000).

\section{In Situ Hybridization for CRF-BP mRNA}

Human CRF-BP riboprobes were prepared from a $500 \mathrm{bp}$ fragment of the human CRF-BP cDNA (generously supplied by Dimitri Grigoriadis, Neurocrine Biosciences, San Diego, CA). This cDNA was contained in a pBluescript SK $(+)$ plasmid (Stratagene, LaJolla, CA). The plasmid was linearized with BamHI (New England Biolabs, Beverly, MA) and transcribed with T7 RNA polymerase (Promega, Madison, WI) for the antisense probe. For the sense control riboprobe, the plasmid was linearized with EcoRI (New England Biolabs) and transcribed with T3 RNA polymerase (Promega).

CRF-BP riboprobe synthesis and in situ hybridization were carried out as previously described (Hsu et al, 1998;

Table I Matched Variables for the Stanley Foundation Neuropathology Consortium

\begin{tabular}{|c|c|c|c|c|}
\hline & Normal controls & Major depression & Bipolar disorder & Schizophrenia \\
\hline Age & $48.1(29-68)$ & $46.4(30-65)$ & $42.3(25-61)$ & $44.2(25-62)$ \\
\hline Sex & $9 M, 6 F$ & $9 M, 6 F$ & $9 M, 6 F$ & $9 M, 6 F$ \\
\hline Race & I4C, IAA & $15 \mathrm{C}$ & I4C, IAA & $13 \mathrm{C}, 2 \mathrm{~A}$ \\
\hline PMI (h) & $23.7(8-42)$ & $27.5(7-47)$ & $32.5(13-62)$ & $33.7(|2-6|)$ \\
\hline mRNA yield & $12 \mathrm{~A}, 2 \mathrm{~B}, 1 \mathrm{C}$ & $1 \mid \mathrm{A}, 2 \mathrm{~B}, 2 \mathrm{C}$ & $13 \mathrm{~A}, 2 \mathrm{~B}$ & $10 \mathrm{~A}, 2 \mathrm{~B}, 3 \mathrm{C}$ \\
\hline
\end{tabular}

Adapted from (Torrey et al, 2000). $A=$ Asian, $A A=$ African-American, $C=$ Caucasian. For mRNA yield, $A=$ excellent, $B=$ good, $C=$ fair, and for side of brain frozen, $\mathrm{R}=$ right and $\mathrm{L}=$ left. 
Lombardo et al, 2001) with the following modifications. One section from each subject was used for in situ hybridization. Sections were brought to room temperature for $10 \mathrm{~min}$ and then fixed for $15 \mathrm{~min}$ in $4 \%$ paraformaldehyde. Proteinase $\mathrm{K}$ treatment was shortened to $5 \mathrm{~min}$. Following in situ hybridization, sections were exposed to a phosphor screen for 5 days and then scanned with a Typhoon Phosphorimager (Amersham Biosciences, Piscataway, NJ) at $50 \mu \mathrm{m}$ resolution. All signal remained within the linear dynamic range of the screens.

To assess the cellular localization of CRF-BP antisense riboprobe signal, all hybridized sections were dipped in Kodak NTB-3 nuclear emulsion (Eastman Kodak, Rochester, NY), developed in D-19 developer (Eastman Kodak) after 2 weeks, and counterstained with $0.1 \%$ toluidine blue.

\section{Image Analysis}

All phosphor images were analyzed using ImageQuant 5.2 software (Amersham Biosciences). Regions analyzed included the following: basolateral amygdala (BL), lateral amygdala (La), entorhinal cortex (Ent), fusiform gyrus (Fus), and an entorhinal gray/white matter transition area (Ent-trans). Because the more dorsal regions of the amygdala were not contained in the coronal sections, the central nucleus could not be analyzed. Background average intensity was first measured in a region of white matter devoid of signal. Rectangular regions of interest (ROI) were then placed over the respective areas. The dimensions in $\mathrm{mm}$ for these ROIs are as follows: BL and La (6.6, 3.2), Ent $(2.7,5.3)$, Fus $(5.3,2.7)$, and Ent-trans $(2.9,4.7)$. Due to the punctate nature of the CRF-BP signal, most areas (except Ent and Fus) were analyzed using the SpotFinder thresholding function. This function detects areas of signal (spots) above threshold, which was set at $1.75 \times$ background. The outcome measure analyzed was total signal volume (total area $\times$ average intensity). Because CRF-BP signal in the cortex was more diffuse, Ent and Fus were analyzed using sum above background in the ROI. In this method, only pixels that are above background are reported. The outcome measure was the volume above background (average intensity of pixels above background $\times$ the number of pixels above background). This measure is analogous to the total signal volume using SpotFinder. All intensity measurements were corrected for background. Some regions of some sections were excluded from analysis due to tissue damage. One section, each from a different subject, was excluded for BL, La, Fus, and Ent-trans, and three sections were excluded for Ent. Additionally, $\mathrm{pH}$ was not reported for one subject, so this sample was excluded from correlations between mRNA levels and $\mathrm{pH}$.

\section{Statistical Analysis}

For each of the five brain regions, there was at least one diagnostic group for which the data were not normally distributed as determined by the Kolmogorov-Smirnov $Z$ test. Various mathematical transformations (ie square-root, logarithmic) failed to normalize the distribution of all the data sets. Therefore, nonparametric analyses were performed with the Kruskal-Wallis $H$ test to determine the effect of diagnostic group on CRF-BP mRNA expression for each gender. Pairwise comparisons of each pathological group to the normal group were done with Mann-Whitney $U$ tests as were gender comparisons for each brain region. Spearman rank correlations were performed to assess the relationship between mRNA levels and post-mortem interval, lifetime antipsychotic dose, subject age, duration of illness, duration of storage, and brain weight. The effects of the categorical variables of gender, brain hemisphere, suicide, history of psychosis, receiving antidepressants at the time of death or smoking status at the time of death on outcome measures were assessed by Mann-Whitney $U$ tests. In subjects reporting current or past substance abuse, the effect of severity of substance abuse or alcohol abuse rated on a scale of 0 to 5 was assessed by a Kruskal-Wallis $H$ test. Tissue section $\mathrm{pH}$ values were normally distributed, and a one-factor ANOVA was used to determine if $\mathrm{pH}$ values differed among diagnostic groups. SPSS 13.0 software (SPSS Inc., Chicago, IL) was used for all statistical analyses.

\section{RESULTS}

\section{Distribution of CRF-BP mRNA in Human Amygdala and Surrounding Areas}

Hybridization using the sense control probe for CRF-BP demonstrated no observable signal (Figure 1). In situ hybridization using the CRF-BP antisense probe demonstrated a distribution of CRF-BP mRNA that is similar to that of the rat (Potter et al, 1992). Specifically, we observed a punctate distribution of signal in amygdala, hippocampus, and in gray/white matter transition areas. Compared to the subcortical regions, CRF-BP mRNA expression was more diffuse in the cortical areas examined (Figure 1).

Microscopic analysis of the emulsion-dipped sections revealed that the punctate distribution of CRF-BP mRNA corresponded to individual cells. The cells expressing CRFBP appeared to be primarily, if not exclusively, neuronal given the large size of the nuclei. Analysis of signal in the gray/white matter transition areas revealed this signal to also be localized to individual cells that were presumably white matter neurons (Figure 2).

\section{Analysis of CRF-BP mRNA Content in Amygdala and Surrounding Areas}

Levels of CRF-BP mRNA expression in tissue obtained from normal subjects varied significantly between brain regions $\left(\chi^{2}=12.68 ; \mathrm{df}=4 ; p<0.05\right)$. The cortical areas (Ent, Fus) tended to have greater expression levels compared with amygdala regions (BL, La) and the Ent-trans (Figure 3a). When looking at CRF-BP mRNA levels in normal males and females (Figure $3 \mathrm{~b}$ ), there was significantly lower expression in females compared to males in the lateral amygdala $(Z=-2.239, p<0.05)$ and a trend for lower expression in females in the basolateral amygdala $(Z=-1.933, p=0.060)$.

Comparing tissue from all diagnostic groups combined, there were no significant effects of hemisphere or gender on CRF-BP mRNA levels in any of the five brain regions examined. In those subjects diagnosed with a psychiatric illness $(n=45)$, there was no difference in CRF-BP mRNA levels based on if the subject died as the result of suicide $(n=20)$, if the subject had a history of psychosis $(n=26)$, 

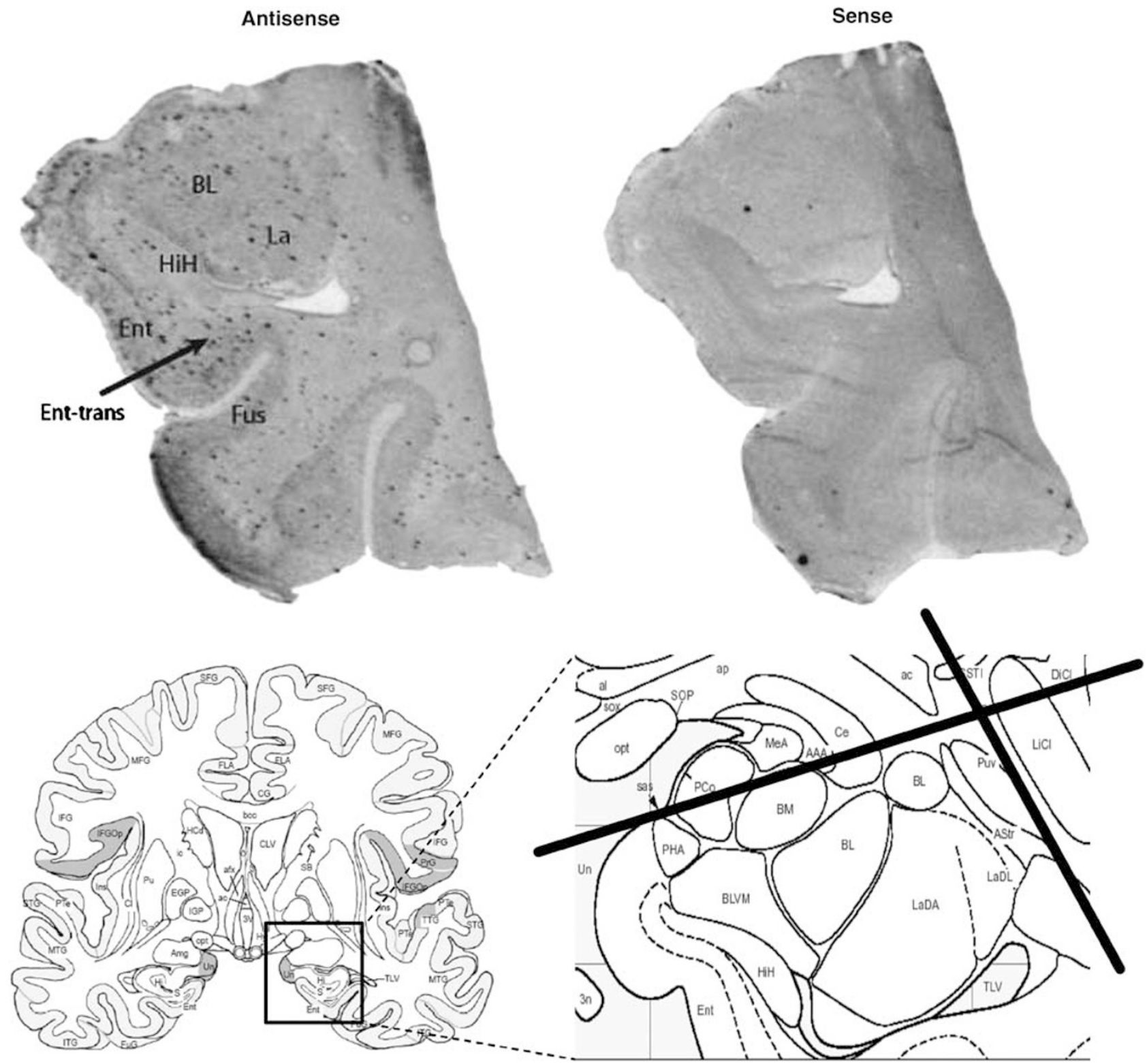

Figure I Representative in situ hybridization for CRF-BP in a human amygdala section (upper left). A sense control probe for CRF-BP revealed no signal (upper right). Note the punctate pattern of signal lying over gray matter areas such as amygdala and cortex, as well as more diffuse signal present in cortex. Signal is also evident in the subcortical white matter. An atlas image of a coronal section of the brain at the level of the amygdala is shown in the lower left, and a detailed atlas image of the amygdala corresponding to the upper half of the tissue section is shown in the lower right (Mai, Assheuer, Paxinos, 1997). The heavy lines represent the cut lines used when the brain tissue was blocked at post-mortem. BL=basolateral amygdala, La $=$ lateral amygdala, Ent $=$ entorhinal cortex, Fus = fusiform gyrus, Ent-trans = entorhinal gray/white transition area, $\mathrm{HiH}=$ hippocampus.

or if the subject was on an antidepressant at the time of death $(n=23)$. Of the 39 out of 60 subjects for whom smoking status was known, being a smoker at the time of death $(n=22)$ did not affect CRF-BP mRNA levels. For those subjects reporting current or past substance abuse $(n=23)$, there was no significant effect of the severity of ethanol abuse or abuse of other substances (severity scale of $0-5$ ) on the level of CRF-BP mRNA in any of the five brain regions examined.

The correlation between CRF-BP mRNA levels and a variety of subject variables was investigated. When examining the entire subject population, there was no statistically significant correlation between CRF-BP mRNA levels and post-mortem interval, duration of tissue storage or brain weight. There was a weak negative correlation between brain weight and level of CRF-BP mRNA in the Ent only $(r=-0.282 ; p<0.05)$. Excluding normals from the analysis, there was no significant correlation between the levels of CRF-BP mRNA and the duration of illness or the age at onset of illness. In a pooled analysis of the bipolar and schizophrenic groups, CRF-BP mRNA levels did not correlate with lifetime antipsychotic dose. Of note was the significant positive correlation between tissue $\mathrm{pH}$ and CRFBP mRNA levels in four brain regions; for the La $(r=0.377$; $p<0.01 ; n=58)$, for the BL $(r=0.331 ; p<0.05 ; n=58)$, for the Fus $(r=0.333 ; p<0.05 ; n=58)$, for the Ent-trans 


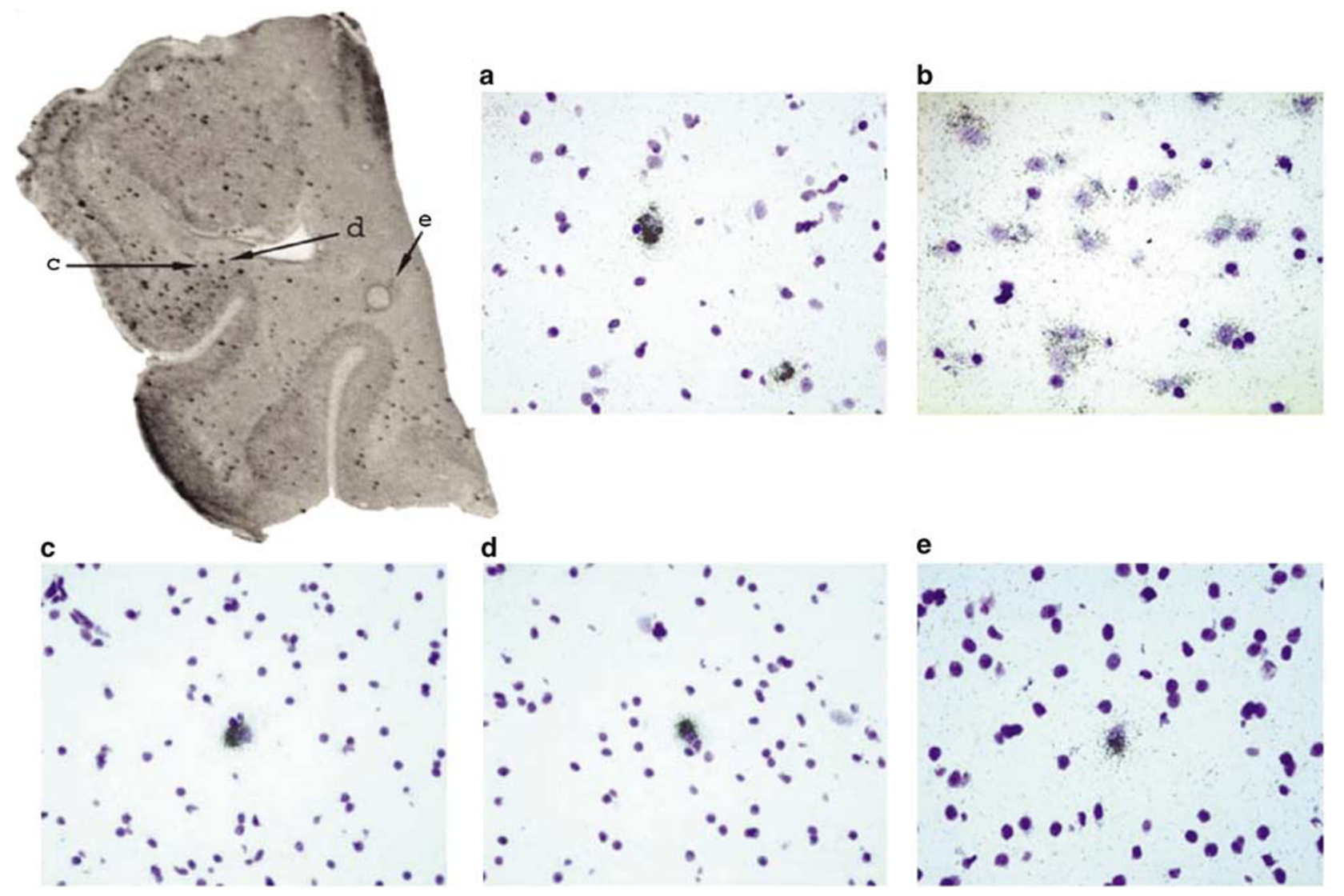

Figure 2 Representative photomicrographs of emulsion-dipped sections following in situ hybridization for CRF-BP. (a) Amygdala. Note the high density of grains overlying large, presumably neuronal, nuclei. (b) Entorhinal cortex. Note the more diffuse and lower levels of grains over neuronal-like nuclei. (c-e) Subcortical white matter. Signal grains are shown to lie over relatively large nuclei that may be interstitial white matter neurons. Individual cells shown in (c-e) are indicated on the in situ hybridization image. Magnification is $\times 40$ except for (e) which is $\times 63$.

$(r=0.273 ; p<0.05 ; n=58)$, and a trend for a positive correlation for the Ent $(r=0.253 ; p=0.06 ; n=56)$. When the correlation between tissue $\mathrm{pH}$ and CRF-BP mRNA levels was examined separately in males and females, the effects of $\mathrm{pH}$ were brain region specific. For males there was a significant correlation between brain $\mathrm{pH}$ and CRF-BP mRNA levels in the La $(r=0.451 ; p<0.01 ; n=34)$ and the Ent $(r=0.350 ; p<0.05 ; n=33)$; whereas, in females the significant correlations were in the BL $(r=0.416 ; p<0.05$; $n=23)$ and Fus $(r=0.461 ; p<0.05, n=24)$.

\section{Basolateral Amygdala}

Because a gender difference was detected in CRF-BP mRNA levels in normals, and since the activity of the human CRF-BP promoter is responsive to estrogen receptors (van de Stolpe et al, 2004), we performed separate nonparametric tests for each gender to determine if there was a significant difference among diagnostic groups in BL CRF-BP mRNA levels. For males, a Kruskal-Wallis $H$ test revealed a significant difference among diagnostic groups $(n=9 /$ group $)$ in BL CRF-BP mRNA levels $\left(\chi^{2}=13.01 ; \mathrm{df}=3\right.$; $p<0.01)$. Pairwise comparisons showed a significantly lower expression of CRF-BP mRNA in the BL in the male bipolar $(Z=-2.58 ; p<0.01)$ and schizophrenic $(Z=-2.71$; $p<0.01$ ) groups compared to the normal group (Figure 4).
For females, there was no significant difference among diagnostic groups ( $n=5$-6/group) for BL CRF-BP mRNA levels $\left(\chi^{2}=1.16 ; \mathrm{df}=3 ; p=0.76\right.$; Figure 4$)$.

Separate pairwise comparisons between males and females revealed a trend for higher CRF-BP mRNA levels in normal males compared to normal females as described previously in Figure 3. There were no significant differences between males and females in any of the pathological groups.

Suicide has been associated with alterations in the CRF system (Merali et al, 2004; Nemeroff et al, 1988). However, Mann-Whitney $U$ tests failed to detect a significant difference in BL CRF-BP mRNA levels in the pathological groups between males that did $(n=12)$ or did not $(n=15)$ commit suicide $(Z=-0.537 ; p=0.591)$ or females that did $(n=8)$ or did not $(n=10)$ commit suicide $(Z=-0.712$; $p=0.476)$.

\section{Lateral Amygdala}

For males, a Kruskal-Wallis $H$ test revealed a significant difference among diagnostic groups $(n=8-9 /$ group $)$ for La CRF-BP mRNA levels $\left(\chi^{2}=9.42 ; \mathrm{df}=3 ; p<0.05\right)$. Pairwise comparisons to the normal group showed a significantly lower expression of CRF-BP mRNA in the BL in the male bipolar group $(Z=-2.59 ; p<0.01)$ with a trend toward 

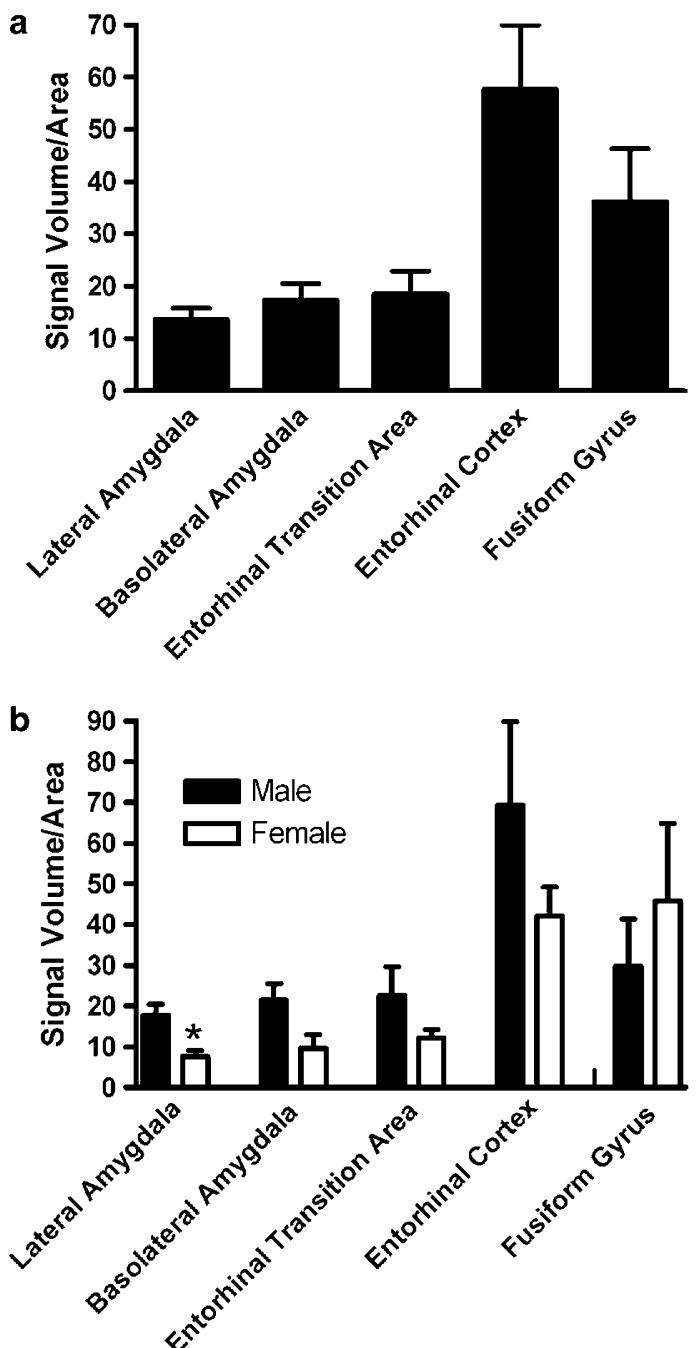

Figure 3 (a) CRF-BP mRNA levels in tissue sections from the normal group. Because the size of the region of interest was different in each brain region, the signal volume was corrected for area measured (signal volume/ area). Kruskal-Wallis $H$ tests revealed a significant difference between brain regions $\left(\chi^{2}=12.68 ; \mathrm{df}=4 ; p<0.05\right)$. The highest levels of expression were seen in the cortical regions with the Ent having twice the signal of the Fus. The expression levels in the other regions were similar to each other but lower than the cortical regions. For each tissue $n=15$, except for $B L$ and Ent where $n=14$; bars are mean + SEM. (b) CRF-BP mRNA levels in tissue sections from males and females in the normal group. Pairwise comparisons with Mann-Whitney $U$ tests revealed a significantly lower level of expression in females compared to males in the lateral amygdala $(* p<0.05)$ with a trend for lower expression in females in the basolateral amygdala $(p=0.060)$. For each tissue, $n=6$ for females and 9 for males, except for BL where $n=5$ for females and 9 for males and Ent where $n=6$ for females and 8 for males; bars are mean + SEM.

lower levels in the schizophrenic group $(Z=-1.89$; $p=0.059$; Figure 5). For females, there was no significant difference among diagnostic groups ( $n=6 /$ group) for La CRF-BP mRNA levels ( $\chi^{2}=1.06 ; \mathrm{df}=3 ; p=0.79$; Figure 5).

Separate pairwise comparisons between males and females revealed significantly higher CRF-BP mRNA levels in normal males compared to normal females, as described in Figure 3. There were no significant differences between males and females in any of the pathological groups.

There was a significant correlation between tissue $\mathrm{pH}$ and La CRF-BP mRNA levels in males. However, $\mathrm{pH}$ values do

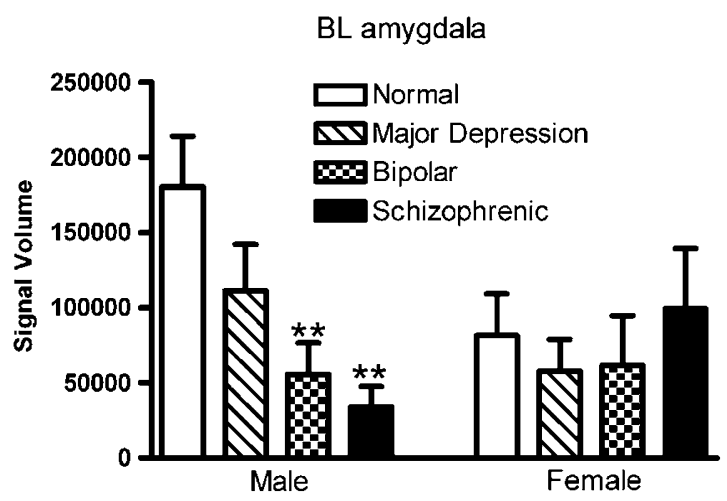

Figure 4 Basolateral amygdala (BL) CRF-BP mRNA analysis. Data represent the amount of CRF-BP mRNA detected in the BL following in situ hybridization and exposure to phosphorimager screens (see Methods and Materials). Bars are mean + SEM. Kruskal-Wallis $H$ tests revealed a significant difference between diagnostic groups in males only $\left(\chi^{2}=13.01 ; \mathrm{df}=3 ; p<0.01\right)$. Pairwise comparisons with Mann-Whitney $U$ tests revealed a significant difference in males between the Normal group and the Bipolar and Schizophrenic groups $(* * x<0.01)$. For males $n=9$ per group and for females $n=5-6$ per group.

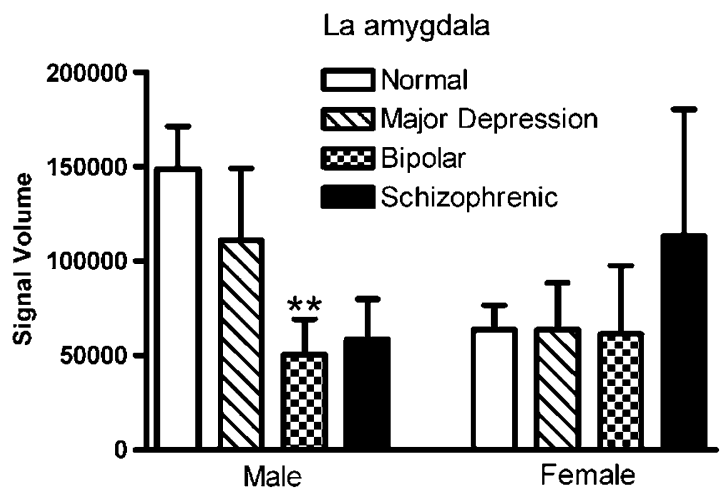

Figure 5 Lateral amygdala (La) CRF-BP mRNA analysis. Data represent the amount of CRF-BP mRNA detected in the La following in situ hybridization and exposure to phosphorimager screens (see Methods and Materials). Bars are mean + SEM. Kruskal-Wallis $H$ tests revealed a significant difference between diagnostic groups in males only $\left(\chi^{2}=9.42\right.$; $\mathrm{df}=3 ; p<0.05)$. Pairwise comparisons with Mann-Whitney $U$ tests revealed a significant difference in males between the Normal group and the Bipolar group $(* * p<0.01)$. For males $n=8-9$ per group and for females $n=6$ per group.

not differ significantly among diagnostic groups for either gender (males $-\mathrm{F}_{3,31}=1.08 ; p=0.371$ and females $-\mathrm{F}_{3,20}=$ $0.532 ; p=0.666)$. Therefore, differences in tissue $\mathrm{pH}$ could not explain the differences in CRF-BP mRNA levels among diagnostic groups.

Finally, Mann-Whitney $U$ tests failed to detect a significant difference in La CRF-BP mRNA levels in the pathological groups between males that $\operatorname{did}(n=11)$ or did not $(n=15)$ commit suicide $(Z=-0.389 ; p=0.697)$ or females that did $(n=8)$ or did not $(n=10)$ commit suicide $(Z=-0.178 ; p=0.859)$.

\section{Other Regions}

No significant differences among diagnostic group means were detected in CRF-BP mRNA levels for Ent, Fus, or the 
Table 2 Analysis of CRF-BP mRNA in Regions Adjacent to Amygdala

Group

\begin{tabular}{lccrr}
\cline { 2 - 5 } Region & Normal & Depression & Bipolar & Schizophrenia \\
\hline Ent-trans & $115030 \pm 27453$ & $135282 \pm 3268 \mid$ & $74464 \pm 20119$ & $1089 \mid 0 \pm 20903$ \\
Ent & $330045 \pm 70388$ & $28|827 \pm 7| 382$ & $218386 \pm 45905$ & $409867 \pm 89 \mid 56$ \\
Fus & $206985 \pm 57962$ & $216857 \pm 6806 \mid$ & $15 \mid 590 \pm 33859$ & $274499 \pm 54254$
\end{tabular}

Measures of CRF-BP mRNA for Ent-trans are the same as those for BL and La above. Due to the more diffuse nature of signal in the cortex, simple volume measurements above background were used for the Ent and Fus (see Methods and Materials). There were no significant differences among the groups for any of these brain regions. Values are means \pm standard error. $n=13-15 /$ group for Ent-trans, and |4-I5/group for Ent and Fus. See Figure I for abbreviations.

Ent-trans areas when nonparametric analyses were performed on males or females (Table 2). Additionally, there were no gender differences in the expression of CRF-BP mRNA for any of the diagnostic groups in the Ent, Fus or Ent-trans regions (data not shown).

\section{DISCUSSION}

To our knowledge, this is the first study to characterize the anatomical distribution of CRF-BP gene expression in the human brain. The distribution of CRF-BP mRNA generally shows a punctate pattern that is similar to that seen in the rat (Potter et al, 1992). The highest levels of expression were seen in the entorhinal cortex and fusiform gyrus with lower levels in the basolateral and lateral amygdala regions and the entorhinal transition area. The expression of CRF-BP mRNA appears to be primarily, if not exclusively, over neuronal-like nuclei, which would also be consistent with that seen in the rat brain. The notable difference compared to the pattern seen in the rat brain is the presence of CRF-BP expression in cells in the gray/white matter transition areas. The relative size of the nuclei expressing CRF-BP in the gray/white matter transitional areas appears to be smaller than cortical or amygdala nuclei, suggesting that these may be subplate interstitial neurons, which are known to be present in these areas in humans (Allendoerfer and Shatz, 1994). It is noteworthy that the ratio of the subplate zone to cortical zone is much larger in humans compared to rodents, reaching a maximum in development of $4: 1$ in humans and $1: 2$ in rodents (Kostovic and Rakic, 1990; Mrzljak et al, 1988). These ratio differences could account for the noticeable difference in interstitial CRF-BP mRNA between rat and human.

Interestingly, gender differences were detected in normal subjects, with CRF-BP mRNA levels tending to be higher in the brain tissue of males compared to females, with the exception of the fusiform gyrus. This observation is the opposite of the gender differences described in the rat pituitary, with higher CRF-BP levels reported in female compared to male rats (Speert et al, 2002). It is not possible to compare our human brain results with rat brain studies, as gender differences in the expression levels of CRF-BP within the rat brain have not been reported. However, in light of published data showing estrogen receptor-dependent regulation of the human CRF-BP gene in vitro (van de Stolpe et al, 2004), it is possible that reproductive hormone differences between males and females may contribute to gender differences in the basal level of CRF-BP expression.

Analysis of the levels of CRF-BP mRNA among the four diagnostic groups revealed that in males there was a significant decrease in BL CRF-BP mRNA in schizophrenia and bipolar disorder and in La CRF-BP mRNA in bipolar disorder with a trend toward a decrease in schizophrenia. The gender difference in the effect of diagnostic group on the expression of BL CRF-BP mRNA is consistent with the possible modulatory role of reproductive hormones on CRF-BP expression in this brain region. The human CRF-BP promoter contains multiple estrogen-responsive element half sites (Behan et al, 1993) and estrogen and its two receptors $(\mathrm{ER} \alpha$ and $\mathrm{ER} \beta$ ) have been shown to modulate CRF-BP promoter activity and expression in vitro. Specifically, both receptors constitutively activated the CRF-BP promoter independent of ligand. However, in the presence of estradiol, ER $\alpha$ upregulated, while $\operatorname{ER} \beta$ repressed, CRF-BP promoter activity (van de Stolpe et al, 2004). Interestingly, the basolateral complex of the human amygdala has been reported to express higher levels of $\operatorname{ER} \beta$ compared to $\operatorname{ER} \alpha$ mRNA (Osterlund et al, 2000). It is therefore possible that estradiol-bound ER $\beta$ might be responsible for BL-specific repression of CRF-BP expression. This is consistent with the trend for lower levels of CRF-BP mRNA in the BL of normal females compared to normal males. Although the hormonal status of the females in this study is unknown, it is reasonable to speculate that many of the subjects were estrogen positive (either premenopausal or on hormonereplacement therapy). Alternatively, it is possible that testosterone might serve to upregulate CRF-BP expression, and computer-aided sequence analysis reveals at least three putative androgen-response elements located in the human CRF-BP promoter (SA Nanda, personal communication). However, because our effects are only seen in the amygdala, the effects of testosterone would have to be in a regionspecific manner. In primates, there appears to be little expression of androgen receptors in the basolateral complex (Choate et al, 1998; Michael et al, 1995), making this possibility less likely.

The male-specific difference between normal and schizophrenic subjects in CRF-BP mRNA levels is interesting because of the known gender differences associated with schizophrenia. For example, research has suggested that compared to females, males have poorer premorbid functioning, a higher incidence of schizophrenia and an earlier age of onset (Salem and Kring, 1998; Tamminga, 
1997). Indeed, in the Stanley Foundation sample, there was a trend for the average age of onset to be lower in males $(20.2 \pm 1.5$ years $)$ compared to females $(27.7 \pm 4.2$ years $)$. While it is possible to speculate that the lower levels of amygdala CRF-BP mRNA seen in male schizophrenics is related to gender differences in the presentation of the illness, the relatively limited data set makes it difficult to draw any specific conclusions.

A possible role for reproductive hormone system alterations in the differences associated with psychopathology is less clear. While basomedial amygdala $\mathrm{ER} \alpha$ mRNA levels have been reported to be decreased in post-mortem tissue from major depression and bipolar disorder subjects compared to normals, no changes were seen with schizophrenic subjects (Perlman et al, 2004). However, ER $\beta$ mRNA changes associated with psychopathology have yet to be reported in the human amygdala.

In the male subjects, we observed decreases in BL and La CRF-BP mRNA in the schizophrenia and bipolar groups. It is important to recognize that these findings are associational and thus can be interpreted in a number of ways. First, reduced amygdala CRF-BP could be a result of psychopathology, perhaps even an adaptive response to the stress associated with these illnesses. However, preclinical studies in our laboratory have demonstrated increases in rat BL CRF-BP mRNA following an acute stressor and no changes in BL CRF-BP mRNA following repeated restraint or ferret stress exposure (Herringa et al, 2004; Lombardo et al, 2001; unpublished observations). Therefore, we would have expected either an increase or no change in BL CRF-BP in response to the stress associated with psychopathology. Alternatively, reductions in amygdala CRF-BP could be a result of general atrophy of this region associated with psychopathology. Some studies have reported decreased amygdala volumes in schizophrenia (Weinberger, 1995), increased or decreased volumes in major depression, and increased volumes in bipolar disorder (Anand and Shekhar, 2003). However, analysis of the number of CRF-BP positive cells in our study reveals no differences in cell counts among diagnostic groups (data not shown). Furthermore, if reduction in $\mathrm{BL}$ and $\mathrm{La}$ CRF-BP mRNA was simply a result of generalized atrophy, one would expect an indiscriminant reduction in gene expression in this region. However, other studies using the amygdala tissue from the same Neuropathology Consortium have reported no changes in BL ER $\alpha$ mRNA or pCREB-immunoreactive cells based on diagnosis (Perlman et al, 2004; Young et al, 2004). Thus, differences in amygdala CRF-BP expression among the diagnostic groups are unlikely to be due to generalized atrophy.

Second, reductions in BL and La CRF-BP expression could represent a predisposing factor to the development or severity of psychopathology. This possibility is interesting since CRF-BP is thought to buffer the actions of CRF. In this case, reduced levels of amygdala CRF-BP would lead to increased levels of free CRF in the amygdala and thus greater activation of amygdala CRF receptors at baseline and/or stress. This in turn could sensitize an individual to the effects of stress on the symptomatology of bipolar disorder and schizophrenia.

The present study is only one of many to report a change in a biochemical marker in post-mortem tissue from subjects diagnosed with bipolar disorder and schizophrenia.
Schizophrenia and bipolar disorder share some features which include subjects from both groups experiencing psychotic symptoms and having been exposed to antipsychotic medications. However, there was no significant difference in the level of CRF-BP mRNA between those subjects with and without a history of psychosis, and there was no correlation between lifetime antipsychotic dose and CRF-BP mRNA levels in the BL. Several other studies performed on the Stanley Foundation Neuropathology Consortium have revealed changes in biological markers in various brain regions only in bipolar and schizophrenic subjects such as glutamic acid decarboxylase 67 protein, protein kinase $\mathrm{C}$ epsilon protein, BDNF peptide, tyrosine kinase A mRNA, and glucocorticoid receptor mRNA (for review see Torrey et al, 2005). Therefore, there appear to be many biochemical changes that are in common between bipolar disorder and schizophrenia that are not present in major depression.

There are two important caveats to this study. First, CRF-BP protein levels were not measured. While it is common for protein changes to occur where mRNA differences are reported, this is not always the case. Second, levels of CRF expression in these tissues have not been determined. Thus, the balance of the CRF system (ie bound vs unbound CRF) in these subjects is not yet known. Future studies should aim to address these issues.

In summary, this is the first study to report the anatomical distribution of CRF-BP mRNA in the human brain, specifically the amygdala region. We found that CRF-BP mRNA was expressed in a punctate pattern in the amygdala and various amygdala-associated cortical regions. In males, reduced levels of BL and La CRF-BP mRNA were associated with schizophrenia and bipolar disorder. This raises the possibility that reduced BL and La CRF-BP might be a risk factor for males in relation to the development and/or maintenance of bipolar disorder and schizophrenia.

\section{ACKNOWLEDGEMENTS}

This work was supported by the Stanley Medical Research Institute, NIH grants MH40855 (NHK), MH65109 (RJH), and the University of Wisconsin HealthEmotions Research Institute. We thank Dr Dimitri E Grigoriadis (Neurocrine Biosciences, San Diego, CA) for the human CRF-BP cDNA. We thank Dr Marilyn J Essex (University of Wisconsin, Madison, WI) for advice on statistical analyses and Dr Charles F Landry (University of Wisconsin) for help with emulsion-dipped sections. We also thank Dr Felice F Borisy-Rudin (University of Wisconsin) for valuable support in obtaining the human brain samples.

\section{REFERENCES}

Allendoerfer KL, Shatz CJ (1994). The subplate, a transient neocortical structure: its role in the development of connections between thalamus and cortex. Annu Rev Neurosci 17: 185-218.

Anand A, Shekhar A (2003). Brain imaging studies in mood and anxiety disorders: special emphasis on the amygdala. Ann NY Acad Sci 985: 370-388.

Arborelius L, Owens MJ, Plotsky PM, Nemeroff CB (1999). The role of corticotropin-releasing factor in depression and anxiety disorders. J Endocrinol 160: 1-12. 
Behan DP, De Souza EB, Lowry PJ, Potter E, Sawchenko P, Vale WW (1995). Corticotropin releasing factor (CRF) binding protein: a novel regulator of $\mathrm{CRF}$ and related peptides. Front Neuroendocrinol 16: 362-382.

Behan DP, Potter E, Lewis KA, Jenkins NA, Copeland N, Lowry PJ et al (1993). Cloning and structure of the human corticotrophin releasing factor- binding protein gene (CRHBP). Genomics 16: 63-68.

Brown GW, Bifulco A, Harris TO (1987). Life events, vulnerability and onset of depression: some refinements. Br J Psychiatry 150: $30-42$.

Choate JV, Slayden OD, Resko JA (1998). Immunocytochemical localization of androgen receptors in brains of developing and adult male rhesus monkeys. Endocrine 8: 51-60.

Claes S, Villafuerte S, Forsgren T, Sluijs S, Del-Favero J, Adolfsson $\mathrm{R}$ et al (2003). The corticotropin-releasing hormone binding protein is associated with major depression in a population from Northern Sweden. Biol Psychiatry 54: 867-872.

Davidson RJ (2002). Anxiety and affective style: role of prefrontal cortex and amygdala. Biol Psychiatry 51: 68-80.

Drevets WC, Raichle ME (1995). Positron emission tomographic imaging studies of human emotional disorders. In: Gazzaniga MS (ed). The Cognitive Neurosciences. MIT: Cambridge, MA. pp $1153-1164$.

Dunn AJ, Berridge CW (1990). Physiological and behavioral responses to corticotropin-releasing factor administration: is CRF a mediator of anxiety or stress responses? Brain Res Brain Res Rev 15: 71-100.

Dunner DL, Patrick V, Fieve RR (1979). Life events at the onset of bipolar affective illness. Am J Psychiatry 136: 508-511.

Hammen C, Davila J, Brown G, Ellicott A, Gitlin M (1992). Psychiatric history and stress: predictors of severity of unipolar depression. J Abnorm Psychol 101: 45-52.

Herringa RJ, Nanda SA, Hsu DT, Roseboom PH, Kalin NH (2004). The effects of acute stress on the regulation of central and basolateral amygdala CRF-binding protein gene expression. Brain Res Mol Brain Res 131: 17-25.

Hsu DT, Chen FL, Takahashi LK, Kalin NH (1998). Rapid stressinduced elevations in corticotropin-releasing hormone mRNA in rat central amygdala nucleus and hypothalamic paraventricular nucleus: an in situ hybridization analysis. Brain Res 788: 305-310.

Hucks D, Lowther S, Crompton MR, Katona CL, Horton RW (1997). Corticotropin-releasing factor binding sites in cortex of depressed suicides. Psychopharmacology (Berl) 134: 174-178.

Kalin NH (1985). Behavioral effects of ovine corticotropinreleasing factor administered to rhesus monkeys. Fed Proc 44: 249-253.

Kalin NH, Shelton SE, Davidson RJ (2000). Cerebrospinal fluid corticotropin-releasing hormone levels are elevated in monkeys with patterns of brain activity associated with fearful temperament. Biol Psychiatry 47: 579-585.

Kalin NH, Shelton SE, Kraemer GW, McKinney WT (1983). Corticotropin-releasing factor administered intraventricularly to rhesus monkeys. Peptides 4: 217-220.

Koob GF, Heinrichs SC (1999). A role for corticotropin releasing factor and urocortin in behavioral responses to stressors. Brain Res 848: 141-152.

Kostovic I, Rakic P (1990). Developmental history of the transient subplate zone in the visual and somatosensory cortex of the macaque monkey and human brain. J Comp Neurol 297: 441-470.

Leake A, Perry EK, Perry RH, Fairbairn AF, Ferrier IN (1990). Cortical concentrations of corticotropin-releasing hormone and its receptor in alzheimer type dementia and major depression. Biol Psychiatry 28: 603-608.

Lombardo KA, Herringa RJ, Balachandran JS, Hsu DT, Bakshi VP, Roseboom PH et al (2001). Effects of acute and repeated restraint stress on corticotropin-releasing hormone binding protein mRNA in rat amygdala and dorsal hippocampus. Neurosci Lett 302: 81-84.

Mai JK, Assheuer J, Paxinos G (1997). Atlas of the Human Brain. Academic Press: San Diego.

Merali Z, Du L, Hrdina P, Palkovits M, Faludi G, Poulter MO et al (2004). Dysregulation in the suicide brain: mRNA expression of corticotropin-releasing hormone receptors and $\mathrm{GABA}(\mathrm{A})$ receptor subunits in frontal cortical brain region. J Neurosci 24: $1478-1485$.

Michael RP, Clancy AN, Zumpe D (1995). Distribution of androgen receptor-like immunoreactivity in the brains of cynomolgus monkeys. J Neuroendocrinol 7: 713-719.

Mitchell AJ (1998). The role of corticotropin releasing factor in depressive illness: a critical review. Neurosci Biobehav Rev 22: 635-651.

Mrzljak L, Uylings HB, Kostovic I, Van Eden CG (1988). Prenatal development of neurons in the human prefrontal cortex: I. A qualitative Golgi study. J Comp Neurol 271: 355-386.

Nemeroff CB, Owens MJ, Bissette G, Andorn AC, Stanley M (1988). Reduced corticotropin releasing factor binding sites in the frontal cortex of suicide victims. Arch Gen Psychiatry 45: 577-579.

Norman RM, Malla AK (1993). Stressful life events and schizophrenia. I: A review of the research. Br J Psychiatry 162: 161-166. Norman RM, Malla AK (1994). A prospective study of daily stressors and symptomatology in schizophrenic patients. Soc Psychiatry Psychiatr Epidemiol 29: 244-249.

Osterlund MK, Gustafsson JA, Keller E, Hurd YL (2000). Estrogen receptor beta (ERbeta) messenger ribonucleic acid (mRNA) expression within the human forebrain: distinct distribution pattern to ERalpha mRNA. J Clin Endocrinol Metab 85: 3840-3846.

Perlman WR, Webster MJ, Kleinman JE, Weickert CS (2004). Reduced glucocorticoid and estrogen receptor alpha messenger ribonucleic acid levels in the amygdala of patients with major mental illness. Biol Psychiatry 56: 844-852.

Potter E, Behan DP, Linton EA, Lowry PJ, Sawchenko PE, Vale WW (1992). The central distribution of corticotropin-releasing factor (CRF)-binding protein predicts multiple sites and modes of interaction with CRF. Proc Natl Acad Sci USA 89: 4192-4196.

Raadsheer FC, van Heerikhuize JJ, Lucassen PJ, Hoogendijk WJ, Tilders FJ, Swaab DF (1995). Corticotropin-releasing hormone mRNA levels in the paraventricular nucleus of patients with Alzheimer's disease and depression. Am J Psychiatry 152: 1372-1376.

Salem JE, Kring AM (1998). The role of gender differences in the reduction of etiologic heterogeneity in schizophrenia. Clin Psychol Rev 18: 795-819.

Schwartz CE, Wright CI, Shin LM, Kagan J, Whalen PJ, McMullin $\mathrm{KG}$ et al (2003). Differential amygdalar response to novel versus newly familiar neutral faces: a functional MRI probe developed for studying inhibited temperament. Biol Psychiatry 53: 854-862.

Speert DB, McClennen SJ, Seasholtz AF (2002). Sexually dimorphic expression of corticotropin-releasing hormone-binding protein in the mouse pituitary. Endocrinology 143: 4730-4741.

Tamminga CA (1997). Gender and schizophrenia. J Clin Psychiatry 58(Suppl 15): 33-37.

Torrey EF, Barci BM, Webster MJ, Bartko JJ, Meador-Woodruff JH, Knable MB (2005). Neurochemical markers for schizophrenia, bipolar disorder, and major depression in postmortem brains. Biol Psychiatry 57: 252-260.

Torrey EF, Webster M, Knable M, Johnston N, Yolken RH (2000). The Stanley Foundation brain collection and Neuropathology Consortium. Schizophr Res 44: 151-155.

van de Stolpe A, Slycke AJ, Reinders MO, Zomer AW, Goodenough $\mathrm{S}$, Behl C et al (2004). Estrogen receptor (ER)-mediated 
transcriptional regulation of the human corticotropin-releasing hormone-binding protein promoter: differential effects of ERalpha and ERbeta. Mol Endocrinol 18: 2908-2923.

Weinberger DR (1995). From neuropathology to neurodevelopment. Lancet 346: 552-557.

Young LT, Bezchlibnyk YB, Chen B, Wang JF, MacQueen GM (2004). Amygdala cyclic adenosine monophosphate response element binding protein phosphorylation in patients with mood disorders: effects of diagnosis, suicide, and drug treatment. Biol Psychiatry 55: 570-577.

Zobel AW, Nickel T, Kunzel HE, Ackl N, Sonntag A, Ising M et al (2000). Effects of the high-affinity corticotropin-releasing hormone receptor 1 antagonist R121919 in major depression: the first 20 patients treated. J Psychiatr Res 34: 171-181. 